\title{
TECHNIQUES FOR DESIGNING VALUE PROPOSITIONS APPLICABLE TO THE CONCEPT OF OUTCOME-ECONOMY
}

\begin{abstract}
A B S TR A C T
The purpose of this article is to analyse and present some techniques that support the design of a value proposition in the context of the outcome-economy. The proposed techniques are intended to support traditional companies in the design of innovative solutions. Also, the discussed techniques were compared to identify the most effective. The study was conducted based on the information available in the literature on the impact of the Industrial Internet of Things on the economy and creation of a value proposition.
\end{abstract}

KEY WORDS

Industrial Internet of Things, Minimum Viable Product, outcome-economy, persona, Value Proposition Canvas, Value Proposition Design

DOI: 10.1515/emj-2017-0006
Corresponding author:

Sylwia Gierej

Bialystok University of Technology, Faculty of Management, Department of

Business Informatics, Poland

e-mail: s.gierej@pb.edu.pl

\section{INTRODUCTION}

The digital revolution changed the perception of the economy and business. Nowadays, the goal of most IT providers is delivering systems that are as intelligent as possible. The increased use of mobile technologies and cloud computing initiates changes in the design of applications and the ways of their use. The possibility of communication between machines and the analysis of the acquired data without human intervention allows to monitor and automate many processes. It drives to the growing importance of the Internet of Things. Therefore, companies are somehow forced to redesign their products and reorganise activities aiming for specific benefits for the client to survive in the market. A value proposition plays an important role in the development of innovative 
products and services. It should be mainly focused on understanding the client preferences, which should be based on the use of techniques to facilitate data collection and analysis of potential recipients.

\section{OUTCOME-ECONOMY}

\section{AS A STAGE IN THE DEVELOPMENT OF THE INDUSTRIAL INTERNET OF THINGS}

The concept of the outcome-economy was created following the observation and analysis of the impact the Industrial Internet of Things (IIoT) had on business development. IIoT is understood as the use of technology in combining the data on people, machines, and processes through the network, contributing to a new direction of economic development (Vermesan \& Friess, 2013). The concept of the Internet of Things was first used by a British entrepreneur, Kevin Ashton in 1999. He used it to name the communication system of the material world with computers by using sensors. This concept involves a combination of clearly identifiable devices via a computer network. Objects thus have the possibility of direct or indirect data collection, processing or exchange (Ashton, 2009). Beyond smartphones and tablets, devises connected within the IoT are also household appliances, lighting, and heating as well as wearable devices, even plants (Harris, 2014). At the turn of 2008 and 2009, the number of devices con- nected to the Internet exceeded 7 billion. It shows the growing importance of the Internet of Things (Magruk, 2015). Now is considered an appropriate moment to initiate the development of the Internet of Things. CISCO Systems Inc. has formulated a broader concept of this phenomenon, namely, the Internet of Everything. This concept defines the connection of people, processes, and data via the Internet (http:// www.ioeassessment.cisco.com/). Analysis of the development of IIoT in economic terms distinguishes four phases of development (Fig. 1).

Phases 1 and 2 include measures feasible in the near future. The first step is to improve operational efficiency. Presented activities are currently being implemented, and will probably accelerate in the next two years. Phases 3 and 4 include forecasted trends, resulting from the growing influence of the IIoT. They are referred to as the outcome economy and pull economy. The outcome economy is based on the quantitative capabilities arising from the application of the IIoT. The economy based on sales products and services will change the direction of the development towards selling measurable outcomes (Industrial Internet..., 2015). "Companies create value not just by selling products and services, but by delivering complete solutions that produce meaningful quantifiable business outcomes for customers" (Barkai, 2016, p. 3). The term outcome should be understood as indicators that reflect the capacity of the enterprise to meet specific market needs, not the product specifications,

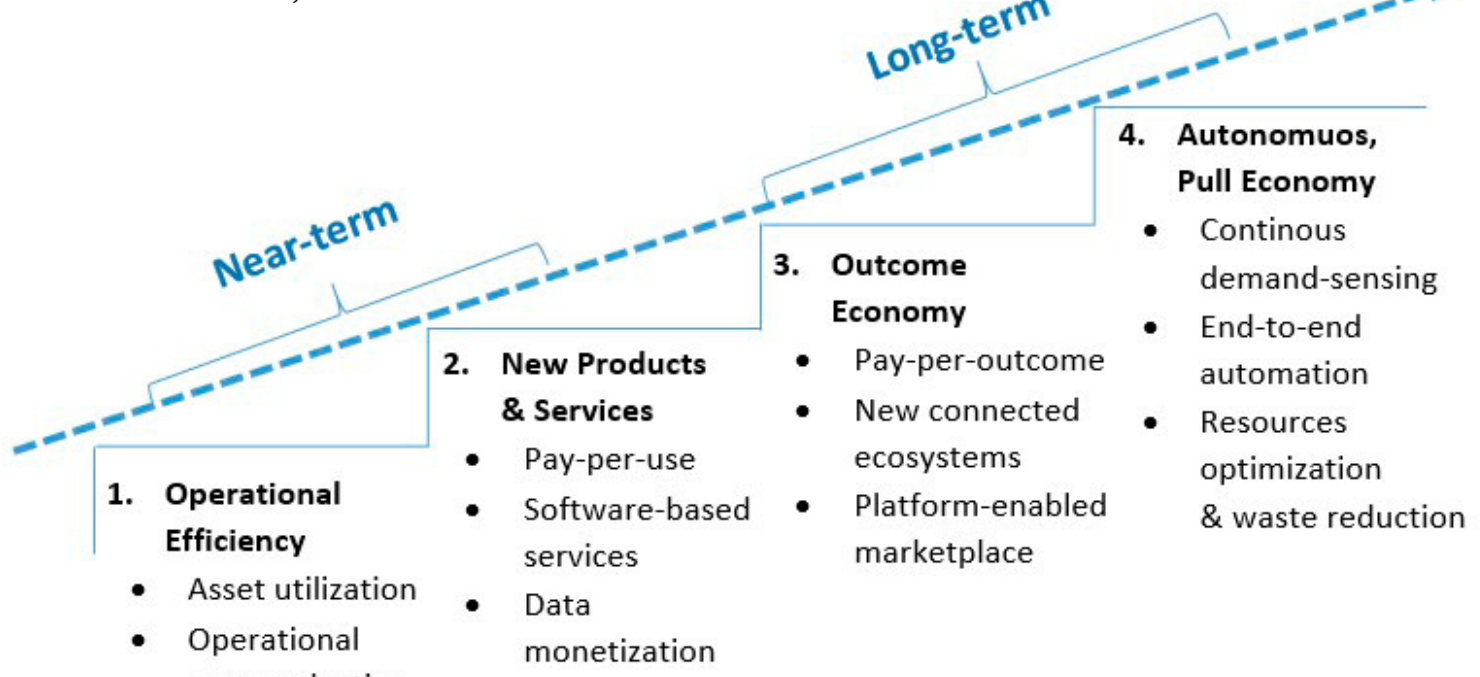

Fig. 1. Phases of the IloT development Source: (Industrial Internet..., 2015). 
for example, horsepower. This is a big change that can bring modification of the basic structures of the industry and market competition. So far, the company based its operation on delivering high-quality products or services, competitive prices, creating a brand by building relationships with customers. The current technologic development forces producers to lean towards a more precise knowledge of preferences and attempts to predict customer needs. Running a business based on cooperation will be an important issue in the economic development. Experts from Accenture, telling about the outcome economy, use the following wording: "Hardware producing hard results". Enterprises operating in the traditional market will have to cooperate with partners who will provide them with the appropriate hardware and software. This will help move products from the physical business world to the digital market (Accenture Technology..., 2015). The main purpose is no longer the new products and services design. Companies will seek to improve the current offer by digital technology. In the long term, companies will be able to generate value without having the necessary resources. They will be able to rely on the assets, that in whole or in part, belong to others (Barkai, 2016). Some examples of the market functioning according to this model are already available, for example, Uber (http://www.uber.com) or Airbnb (http://www.airbnb.com). This solution provides the customer with the best value proposition resulting from the purchase of offered goods. The above-mentioned actions lead to phase 4 , which is the spread of the IIoT in every industry. As a result, it leads to the possibility of determining the level of demand in realtime and highly automated and flexible production networks. The described phenomenon is referred to as the pull economy (Industrial Internet..., 2015).

\section{IMPORTANCE OF THE VALUE PROPOSITION IN THE CONTEXT OF THE OUTCOME-ECONOMY}

In practice, the concept of a value proposition is often thought to be the same as an offer of the company. However, the value proposition is not about presenting specific products or services offered by the company. The value proposition is the reason why customers choose the offer made by a company rather than its competition. In other words, the value proposition is the aggregate of benefits provided by custom- ers using products or services (Osterwalder \& Pigneur, 2010).

The value proposition consists of a defined set of components that meet the specific needs of a particular group of customers. These elements can be either quantitative or qualitative. The elements of a quantitative nature include, inter alia, price, speed, efficiency, lower costs. A group of elements of a qualitative nature may be: innovation, efficiency, design, brand, availability, convenience, and utility (Osterwalder \& Pigneur, 2010). Great value propositions should have the following set of features (Osterwalder et al., 2014, pp. 72-73):

- Embedded in a great business model;

- Focused on jobs, pains, and gains that matter to most customers;

- Focused on unsatisfied jobs, unresolved pains, and unrealized gains;

- Targeting few jobs, pains, and gains, but doing so extremely well;

- Going beyond functional jobs and addressing emotional and social jobs;

- Aligned with how customers measure success;

- Focusing on jobs, pains, and gains that a lot of people have or that some will pay a lot of money for;

- Differentiating from the competition in terms of jobs, pains, and gains that customers care about;

- Outperforming competition substantially on at least in one dimension;

- Difficult to copy.

Based on the presented definition of the outcomeeconomy, which is oriented to the result of the actions, a value proposition can be considered as one of the key elements of corporate strategy. It should also be noted that the outcome-economy is one of the stages of development of the IIoT. Innovative solutions that are the result of technologic development are exposed to a high risk of failure in the market. This is the argument for companies that choose to introduce this type of goods, and which should attach great importance to examining the interests and needs in relation to the proposed solution.

New technologies contribute to the development of new habits and behaviours. These, in turn, are the new sources of economic value. This gives rise to the need for more innovative solutions. The ability to deal with this cycle is not dependent on the capabilities of machines and networks but on the substantial changes in the process value generation (Barkai, 2016). This is a big challenge for current managers, who develop a working method based on the quanti- 
tative analysis. This option is helpful in the case of known solutions, which have already been verified by the market. The problem arises when the company deals with creating innovative products and services. Then, it is not possible to analyse the data, because a company simply has none before testing the solution, at least in the form of a prototype. Managers should have the ability to distinguish optimization measures for the current state of implementation of innovations. This does not mean that they should not in any way verify and collect data before the introduction of the new offer to the market. A compromise is to use advanced analytical tools that do not work well for innovative actions in favour of design methods. Managers should verify the innovative ideas on a small scale, so as not to incur high costs at the very beginning of the project. Data should be generated by conducting experiments. Continuous experimentation helps to make a suggested solution more convincing as well as produces new data. By doing so, modern managers can keep their analytical standards to a certain extent without sacrificing them to innovation because of insufficient information (Martin, 2014).

\section{SELECTED TECHNIQUES USED IN THE PROCESS OF DESIGN OF A VALUE PROPOSITION}

\subsection{DESCRIPTION OF THE PROCESS OF DESIGN OF VALUE PROPOSITIONS BASED ON SELECTED CONCEPTS}

The vast majority of the methods used to define the value proposition comes from start-ups - innovative ventures looking for a scalable business model. They are the most versatile and successful and can be used in enterprises, which have so far operated in the traditional market and decided to introduce their offer on the digital market. Before discussing some design methods, we should look at the process of design of a value proposition. The author decided to compare three approaches to building value propositions, and then indicate the necessary steps in this process.

The first is the concept of Customer Development, which assumes a division of all activities associated with customers into separate processes and incorporates them into four stages. The first two stages relate to the search for the right business model, while two others - to the implementation of the defined and verified positive business model. However, bearing in mind that the key role in the described approach fully corresponds to the client needs, it is possible to look at it in terms of creating value propositions. Steps of the customer development methodology are presents the following diagram (Fig. 2). Stop signs and arrows in the diagram indicate the need for experimentation, verification and implementation of any changes (Blank \& Dorf, 2012).

The second analysed concept is running the Lean methodology. It is defined as "the systematic process of iterative transition from plan A to plan B effectively, even before running out of resources". The development of the initial action plan should be the first step in creating innovative solutions. It should focus on defining the problem and groups of customers of the company. The next step is to consider the elements that may pose the biggest threat. In most cases, the biggest threat is to work on a solution that ultimately is not intended for their audience. For this reason, first, the focus should be on elements that are associated with the highest risk (Maurya, 2012). The development of innovative solutions can be divided into three stages: Problem/Solution Fit, Product/Market Fit, and Scale (Fig. 3).

The third approach discussed is the idea, which is derived from the concept of Business Model Canvas (BMC). In the business model per Osterwalder, value proposition it is one of the fundamental elements necessary for a profit of a company. Continuing the work, the author of this concept developed a scheme of conduct in the value proposition design. Under

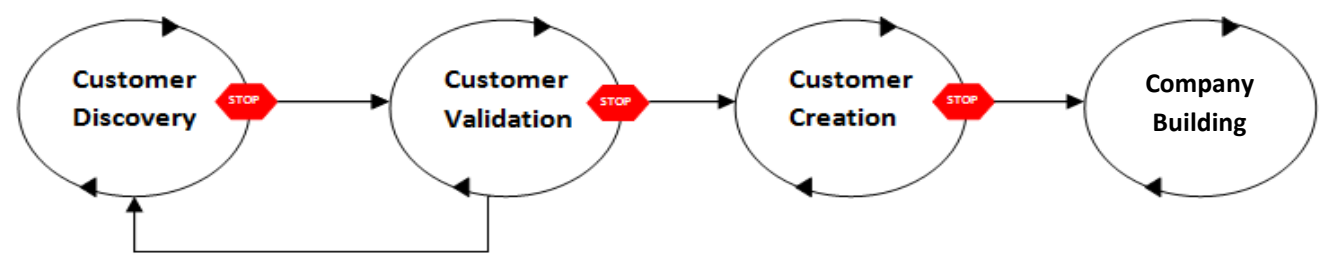

Fig. 2. Steps of the customer development methodology

Source: (Blank \& Dorf, 2012). 


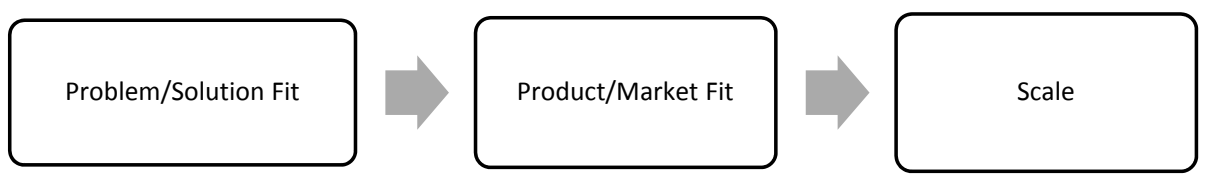

Fig. 3. Three stages of the start-up development

Source: (Maurya, 2012).

this scheme, four steps are distinguished (Osterwalder et al., 2014):

1. Canvas - at this stage, the author proposes the use of two patterns: Customer Profile and Value Map, which will indicate the main characteristics, needs and concerns of potential customers, and then compare them with the benefits offered by the company.

2. Design - prototyping solutions to verify the developed assumptions.

3. Test - conducting experiments and analysis of the collected data to minimize a risk.

4. Evolve - the introduction of the product while continuing monitoring and analysing performance, and possible modification of assumptions.

After comparing the presented concepts, it turns out that all of them are based on a very similar flow chart. The first step is a preliminary analysis of the profile of a potential customer, its problems and needs, and then a summary of the features of the proposed solution. In other words, the company initially verifies that the offered product or service has any value to the customer. The next step should be to test assumptions rather than go forward with the project implementation, as it happens in most cases. The obtained feedback makes it possible to change the product in the way that increases the value proposition. This will allow the company to minimize the risk of losses incurred in the form of expenditures that occur in the absence of a product on the market. The final step is the introduction of the final product on the market. This does not mean the end of the analysis of feedback from customers as it should be continuously monitored and analysed. sis of data on potential customers and tested solutions. The author decided to describe the techniques and tools that are currently gaining popularity. Most of them are based on visual creation, analysis, and exchange of information.

The first technique is the approach proposed by Osterwalder, already mentioned in the previous section. It is the template of the Customer Profile and the Value Map. It is based on the concept of the Business Model Canvas (Fig. 4). It involves creating a business model with the use of a template consisting of nine fundamental elements. A value proposition is placed in the central part of the model (Osterwalder \& Pigneur, 2010).

The primary tool for supporting the development of the contents of fields that describe the customer segments and the value proposition is the Empathy Map (Fig. 5). The use of the Empathy Map aims to develop a profile of a potential customer. It helps to go beyond the typical demographic characteristics of the target audience and better understand the environment, behaviour, concerns and aspirations of its people. The acquired knowledge helps to build more efficient business models, and the creation of the customer profile leads to the development of a better value proposition, efficient methods of contact with customers, and more appropriate relationship with them. In other words, the customer profile of the customer to better understand what it is willing to pay (Osterwalder \& Pigneur, 2010).

The Value Proposition Canvas (VPC, Fig. 6) is to discuss and design connections between the Empathy Map and fields of the BMC. VPC focuses exclusively on two fields maps, namely value proposition and

\subsection{Characteristics \\ OF SELECTED TECHNIQUES \\ FOR THE DESIGN OF A VALUE PROPOSITION}

The literature provides several techniques for the design of a value proposition. Their main purpose is to facilitate the collection and analy-

\begin{tabular}{|c|c|c|c|c|}
\hline \multirow[t]{2}{*}{$\begin{array}{c}\text { Key } \\
\text { Partners }\end{array}$} & $\begin{array}{c}\text { Key } \\
\text { Activities }\end{array}$ & \multirow[t]{2}{*}{$\begin{array}{c}\text { Value } \\
\text { Proposition }\end{array}$} & $\begin{array}{c}\text { Customer } \\
\text { Relationships }\end{array}$ & \multirow[t]{2}{*}{$\begin{array}{l}\text { Customer } \\
\text { Segments }\end{array}$} \\
\hline & $\begin{array}{c}\text { Key } \\
\text { Resources }\end{array}$ & & Channels & \\
\hline \multicolumn{2}{|c|}{ Cost Structure } & \multicolumn{3}{|c|}{ Revenue Streams } \\
\hline
\end{tabular}

Fig. 4. Business Model Canvas

Source: (http://www.businessmodelgeneration.com/, 2016). 


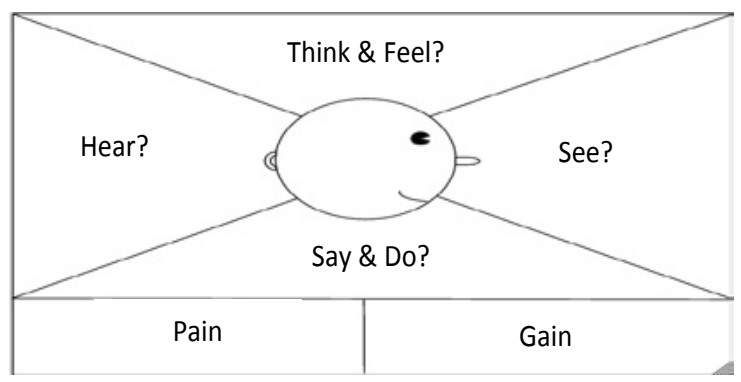

Fig. 5. Empathy Map

Source: (Osterwalder \& Pigneur, 2010).

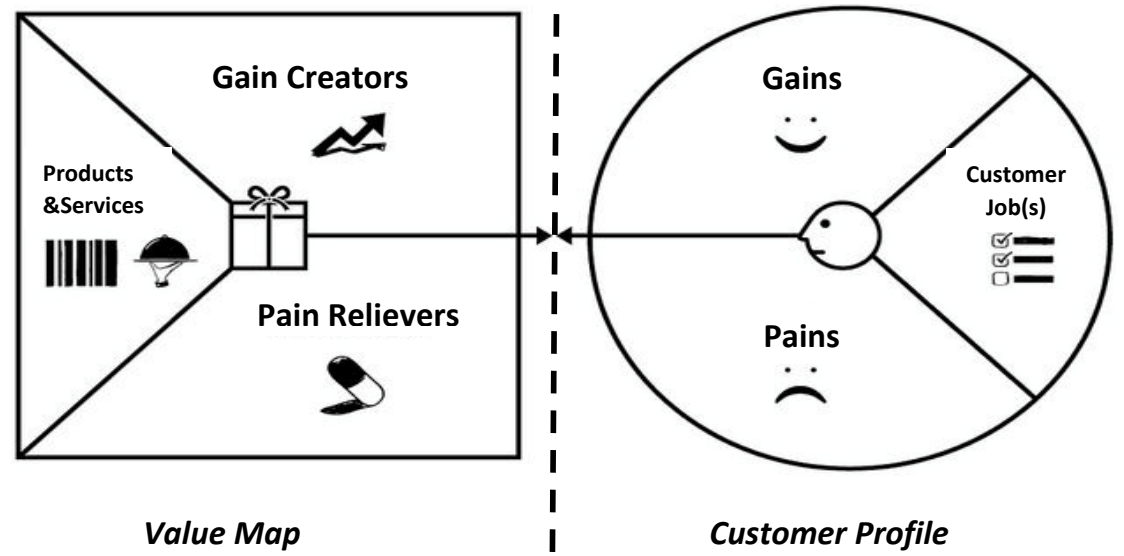

Fig. 6. Value Proposition Canvas

Source: (Osterwalder et al., 2014).

customer segments. Its task is to design connections (distribution channels and customer relationships), to create the products best suited to the needs of its customers. On the one hand, VPC provides the analysis of the market and customer expectations, on the other hand, it determines the tasks that must be performed to match the expectations. It may happen that customer expectations are also concerned with the way a service or product is built, and will force the company to reorganise the infrastructure (Osterwalder et al., 2014).

Below characterized individual elements VPC:

- Customer Job (s): The beginning of the analysis should be a thorough understanding of the target group. It should try to find out and analyse the tasks performed by customers every day. Attention should be focused on matters concerning the problem area related to the proposed solution.

- Pains: This element is designed to identify any obstacles that arise during the planning and implementation following the above-mentioned tasks. It will be all kinds of negative emotions, risks, contingencies, and costs. Consider the solutions currently used by customers and what they consider to be too expensive, difficult or annoying.

- Gains: The next step will be to determine the benefits of these tasks. The benefits can be any kind of positive emotions, social benefits, satisfaction, savings, and increased profits. The focus should be on finding out what pleases the customer, the solutions he/she likes, and things that make his/her life better.

- Products \& Services: Having developed the profile of the client, the company can offer a solution that is a value proposition. In the beginning, it should note products and services that a value proposition contains.

- Pain relievers: Creating value for the customer to either relieving the pain or strengthen the applicable benefits. It should be considered how the proposed solution affects the pain of the potential customer.

- Gain Creators: It should also look at the benefits offered to the customer by the proposed product. It should refer to a predetermined positive aspect, which is desired by the customer.

The analysis of the customer needs, benefits and pains clarifies at least some of the proposals that the company can offer. It should examine each of the proposals using the VPC. The right side of the canvas should remain unchanged, and the left side should produce several solutions and compare them with each other. It can also describe the solution proposed by the competition and make the comparison with the own product. The Value Proposition Canvas is a starting point to begin work on the conceptual idea. There is no need to focus immediately on a full business model, but to explore customer needs and examine possible solutions. The advantage of the canvas is also to draw attention to two important areas of value creation for the customer: benefits and pains. That is what they should look for in a unique value proposition for your product or service (Osterwalder et al., 2014).

Create a persona is another technique, aimed at creating an image of a potential customer and aiding the design of a value proposition. Persona is a model 
of a typical user of a product. The characteristics of a persona are developed based on the analysis of data obtained from tests performed on users. Appropriate use of the findings supports strategic actions related to the objectives and functionality of the designed solution. A persona should be developed in the initial phase of creating a prototype because the product should be developed and optimized for users. Information about users is acquired based on research, such as in-depth individual interviews, focus group interviews, surveys, statistics of website visits and observations. They allow getting information on the objectives and motives of behaviour and the impact of the environment on the user. Studies necessary to create a persona are costly and time-consuming. However, to the result is a developed model of a potential user. Archived data can be used. In the case of construction of

a company website, there is a breath of customer information on marketing or sales. By creating a persona, a prototype is created based on the habits and activities of the target group, and not the characteristics of a designer. This allows keeping only the necessary functions, all of which will be used by the potential user (Kasperski \& Boguska-Torbicz, 2008).

The analysis of the customer profile and the desired characteristics of the solutions is followed by the stage of creating the project product or service. It should prepare a prototype that will be used to test the solution on a small scale. One of the techniques is used in the preparation of a prototyping under the Viable Minimum Product (MVP). This is a version of the solution that is minimally ready for the market. It is sufficiently specific to show the prospective customer value and allow the company to measure the interest of the customer. The main objective of the creation of the MVP is to collect as much information as possible with the least effort. This approach allows testing the validity of the idea. This gives a huge advantage over the classical approach to making products for sale. The classic approach assumes that the process starts with the product hitting the market, i.e. with market research, approval, logistics, manufacturing, marketing, sales, and customer service. It is a very expensive operation, which may prove unsuc- cessful. The MVP helps to save time and costs and to carry out consumer research on a specific product, service, and application (Maurya, 2012).

Based on the information available in the literature, the assessment was made considering the following criteria: the cost of the use of technique, ease of use, required expertise and equipment, and understanding of the technique by all members of the organisation. The rating of techniques was presented in Table 1.

The cheapest, yet easiest to use techniques are the
Tab. 1. Rating of the techniques for the selected criteria

\begin{tabular}{|l|c|c|c|c|}
\hline \multicolumn{1}{|c|}{ Criterion } & $\begin{array}{c}\text { EMpathy } \\
\text { MaP }\end{array}$ & $\begin{array}{c}\text { Value } \\
\text { Proposition } \\
\text { CANVAS }\end{array}$ & $\begin{array}{c}\text { Minimum } \\
\text { VIAble } \\
\text { Product }\end{array}$ & Persona \\
\hline Costs & $* * *$ & $* *$ & $*$ & $*$ \\
\hline Ease of use & $* * *$ & $* * *$ & $* *$ & $* *$ \\
\hline Required specialised expertise & $* * *$ & $* * *$ & $* *$ & $* *$ \\
\hline Required specialized infrastructure & $* * *$ & $* * *$ & $* * *$ & $* * *$ \\
\hline Understanding by all members of the organisation & $* * *$ & $* * *$ & $*$ & $* * *$ \\
\hline
\end{tabular}

Source: author's elaboration based on (Osterwalder \& Pigneur, 2010; Osterwalder et al., 2014; Maurya, 2012;

Empathy Map and the Value Proposition Canvas. They do not require specialized facilities or expertise or skills. They can be used successfully at the beginning of work, as well as supplemented with additional information in the later stages of a project. They can provide the basis for two other techniques: persona and MVP. Their use is associated with higher costs because they require more detailed information about potential users. In addition, in the case of the MVP, the organisation creates the basic test version of the product, which also requires additional funding, staff with appropriate skills and proper technological facilities.

\section{CONCLUSIONS}

Development of technologies contributes to changes in every aspect of life. The digital revolution has a significant impact on business. The use of technologies in combining the data on people, machines, and processes through the network improves business operations. Attempts are made to enrich the physical goods with features based on digital technology, which can raise the value proposition of a company. Development of the IIoT drives the economy 
toward the creation of companies whose business models are focused on providing customer-specific values and benefits. The presented techniques are used in the process of designing value propositions. They are mainly used in the initial stage of the process, the aim of which is to accurately define preferences of potential customers. Creating a customer-tailored solution increases the chance of greater interest in the product while minimizing the risk of an unfortunate investment. The use of such techniques is essential for creating innovative products, as in the case of such solutions often lack data, based on which managers can make decisions. The process of creating a value proposition should start with the use of techniques, which are simple and cheap to use. Such techniques include, among others, Empathy Maps and the Value Proposition Canvas. Thanks to them, an organisation is able to develop the initial product vision. To verify the initial assumptions, another technique can be used, namely, the Minimum Viable Product. It allows you to test the basic functions of the product and obtain feedback from customers to design the final solution.

\section{ACKNOWLEDGEMENTS}

The research was conducted within S/WZ/1/2014 project and was financed from Ministry of Science and Higher Education funds.

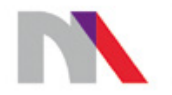

\section{Ministry of Science} and Higher Education

Republic of Poland

7th International Conference on Engineering, Project, and Production Management (EPPM2016) was financed in the framework of the contract no. 712/P-DUN/2016 by the Ministry of Science and Higher Education from the funds earmarked for the public understanding of science initiatives.

7th International Conference on Engineering, Project, and Production Management (EPPM2016) finansowana w ramach umowy 712/P-DUN/2016 ze środków Ministra Nauki i Szkolnictwa Wyższego przeznaczonych na działalność upowszechniającą naukę.

\section{LITERATURE}

Ashton, K. (2009). That's Internet of Things. RFID Journal. Retrieved from http://www.rfidjournal.com/articles/ view?4986/j.em.2016.10.31

Vermesan, O., \& Friess, P. (2013). Internet of Things: Converging Technologies for Smart Environments and Integrated Ecosystems. Aalborg, Denmark: River Publishers.

Harris, M. (2014). The Internet of Trees. IEEE Spectrum.

Magruk, A. (2015). The Most Important Aspects of Uncertainty in the Internet of Things Field - Context of Smart Buildings. Procedia Engineering, 122, 220-227.

Cisco Systems, Inc. (2016). Retrieved from http://ioeassessment.cisco.com/.j.em.2016.10.05

O'Halloran, D., \& Kvochko, E. (2015). Industrial Internet of Things: Unleashing the Potential of Connected Products and Services. World Economic Forum. DavosKlosters, Switzerland.

Barkai, J. (2016). The Outcome Economy: How the Industrial Internet of Things is Transforming Every Business.

Accenture Technology Vision 2015. Retrieved from http:// techtrends.accenture.com/us-en/business-technology-trends-report.html

Blank, S., \& Dorf, B. (2012). The Startup Owner's Manual Vol. $1^{\text {tx }}$ The Step-by-Step Guide for Building a Great Company. Pescadero, USA: K\&S Ranch Publishing Division

Osterwalder, A., Pigneur, Y., Smith, A., Bernarda, G., \& Papadakos, P. (2014). Value Proposition Design. New Jersey, USA: John Wiley \& Sons, Inc.

Osterwalder, A., \& Pigneur, Y. (2010). Business Model Generation: A Handbook for Visionaries, Game Changers, and Challengers. New Jersey, USA: John Wiley \& Sons, Inc.

Martin, R. L. (2014). Two Words That Kill Innovation. Harvard Business Review. Retrieved from https://hbr. org/2014/12/two-words-that-kill-innovation

Maurya, A. (2012). Running Lean: Iterate from Plan A to a Plan That Works. USA: O’Reilly Media, Inc.

Kasperski, M., \& Boguska-Torbicz, A. (2008). Projektowanie stron WWW. Użyteczność w praktyce [Website design. Usability in the practice]. Gliwice, Poland: Helion. 